\title{
Improving Agricultural Commodities Value Chains: How to Collaborate with the Private Sector for the Benefit of Smallholder Farmers
}

\author{
Hendrik C Knipscheer \\ Winrock International, 2101 Riverfront Drive, Little Rock, Arkansas 72202, USA \\ hknipscheer@winrock.org
}

\begin{abstract}
Previous research and development project interventions have mainly focused on the increase on agricultural productivity. These projects were typically supply-driven and lacked a clear market pull. One solution to this problem is to pursue a demand-led approach which is only possible when private sector stakeholders are actively collaborating. Key is the identification of stakeholders along the value chain. The collaboration with the private sector is referred to as Public-Private Partnerships (PPPs). PPPs is a new development assistance model that builds on common interests between private companies, civil society organizations and public-sector agencies. The Partnership for Safe Poultry in Kenya (PSPK) Program is an example of a successful PPP project. Winrock International was the implementing NGO and co-funding was provided by USAID. The goal of PSPK was to promote safe indigenous poultry production and freedom from poultry diseases, generating high levels of income for smallholder families. PSPK facilitated the indigenous poultry sector stakeholders to commonly define sector growth goalsand commit to actions to meet those goals. The project enabled smallholder producers to invest in facilities and appropriate technologies and apply best management practices that increase productivity and profitability, and that assure the biosecurity of their flocks and the safety of poultry meat and eggs. Within two years indigenous Kenyan poultry meat and eggs from bio-secure smallholder flocks became recognized for high its quality and gained a premium value. These added values were being passed on to the producers' groups. A key instrument wasthe development of 11 bio-secure demonstration farms where chick mortality decreased from about $50 \%$ to less than $10 \%$, average price increased by $7.5 \%$ per $\mathrm{kg}$ of bird live weight, and poultry numbers among the 291 members ( $57 \%$ females) of the demonstration farms increased by as much as $72 \%$. Via these demonstration farms up to 7,000 households have been reached indirectly. The project proved that a previously ignored smallholder livestock sector can be turned around and become a profitable business.
\end{abstract}

Key Words: Market-Driven Development, Value Chains, Stakeholders, Backyard Poultry

\section{INTRODUCTION}

Attempts to increase small farmer incomes include a long history of agricultural research and extension efforts focused on increasing livestock productivity mainly resulting in the expansion of the number of medium and large-scale commercial farms. Yet Asia's poor smallholders continue to struggle and must often seek off-farm income to supplement their meager agricultural earnings. This is especially true for livestock, as the role of its production among smallholders is a complicated one, with multiple purposes and benefits measured over several years. One of the more positive aspects of livestock development is that the demand for livestock products generally outpaces the demand for other agricultural products. At the 1996 international workshop at Parapat, North 
Sumatra, Knipscheer, $\mathrm{Nu} \mathrm{Nu}$ San et al. estimated an annual growth in demand for mutton to be more than 8 percent. As livestock products (e.g. meat, eggs) are typically consumed by the more affluent segments of society, livestock sector development is an important mechanism for the transfer of purchasing power from the affluent segment of society to the rural poor. During my career as an economist I have strived to reach smallholder farmers and to facilitate the introduction of more profitable management practices to such target groups. First, I aimed to do this as an agricultural extension agent in Ivory Coast, then as a crop economist at one of the international research centers (IITA, the International Institute of Tropical Agriculture in Nigeria), thereafter as a livestock economist here at ICARD in Indonesia, and finally in my capacity as a project manager at Winrock International, a US-based non-for profit (NGO) originally funded by the Rockefeller family. I would like to share some lessons learned during the last 40 years, in particular, the importance of seeking collaboration with the private sector.

Previous research and development project interventions focused mainly on the increase in agricultural productivity with few post-harvest interventions. These projects were typically supply-driven and lacked a clear demand pull. The introduction of such innovations resulted often in higher farm production which the local market was not able to absorb. One solution to this problem is to pursue a market-driven approach which is only possible when private sector stakeholders actively collaborate. Key is the identification of stakeholders in the value chain that trade directly with consumer groups. In the agricultural annual crop and tree crop sector, agricultural processors such as Nestle, Unilever, Cargill, and Cadbury are examples of such private companies. When the SmallRuminants Collaborative Research Program (SR-CRSP) was active in Indonesia in the 1980s and 90s, ICARD experimented with a pilot project to try out the opportunities for a private animal health delivery network within the country. During the early 90s in North Sumatra, Kartamulia et al. compared the public-supported drug delivery system with the private sector delivery system. The study found that the scope of expanding the role of the private sector was promising and that a redefinition of government livestock services should be considered by phasing out the delivery of subsidized drugs because of their limited and unreliable availability, and the lack of associated services such as clear instructions and demonstrations regarding the application of the drugs.

This paper is divided into three sections. First, I will present the strengths and weaknesses of each of the three main sectors of any society: the public sector, the private sector and the NGO sector. Second, I will explain the advantages and disadvantages of Public-Private Partnerships. Third, I will touch on the importance of the value chain concept by using the example of successful collaboration between the three sectors to improve the smallholder indigenous poultry sector in Kenya, a project introduced and implemented by Winrock International.

\section{THE THREE SOCIETY SECTORS - STRENGTH AND WEAKNESSES}

Collaboration between entities of the public and private sector is referred to as Public-Private Partnership or PPP. Civil society and the NGO sector often participate in this type of collaboration. PPP is a relatively new development assistance model that builds on common interests between private companies, civil society organizations and public-sector agencies which define a common specific development goal and combine their resources and strengths towards reaching that goal. A typical example of such a common goal is the development of a well-functioning supply chain. The strength of the private sector includes its technical and managerial expertise, access to private financial 
capital, eagerness to expand into new markets, and a penchant for technical innovation. The strength of the NGO (Civil Society) sector is its ability to reach marginal groups, organize communities (thereby reducing transaction costs), attract donor funds, and its potential role as an honest broker. The strength of the public sector is its ability to t create an enabling environment and to mobilize public resources. Table 1 summarizes the general strengths of each sector organization.

Table 1. Strengths of the three society sectors

\begin{tabular}{lll}
\hline \hline Public & \multicolumn{1}{c}{ Private } & \multicolumn{1}{c}{ NGO } \\
\hline $\begin{array}{l}\text { Supports regulatory } \\
\text { environment }\end{array}$ & $\begin{array}{l}\text { Provides technical \& } \\
\text { management expertise } \\
\text { Improves infra-structure } \\
\text { Mobilizes financial } \\
\text { resources } \\
\text { Pursues innovations }\end{array}$ & Reaches marginal groups \\
Maintains law \& order & $\begin{array}{l}\text { Mobilizes charitable } \\
\text { resources }\end{array}$ \\
$\begin{array}{l}\text { Promotes information and } \\
\text { knowledge sharing }\end{array}$ & Commits to long-term goals & $\begin{array}{l}\text { Organizes groups/reduces } \\
\text { transaction costs }\end{array}$ \\
\hline
\end{tabular}

The weakness of the private sector includes its lack of understanding of smallholder farmers and a distrust in their capacities, short-term salary incentives, and a lack of social responsibility in specific regions. The weakness of the public sector includes its tendency to control, and a lack of urgency (e.g. not meeting deadlines). The civil society organizations often suffer from amateurism and a limited focus. See Table 2.

The notion underlying PPP projects is that through collaboration among the three sectors, each sector's strength will compensate for the other's weaknesses.

Table 2. Weaknesses of the three society sectors

\begin{tabular}{lll}
\hline \hline Public & \multicolumn{1}{c}{ Private } & \multicolumn{1}{c}{ NGOs } \\
\hline $\begin{array}{l}\text { Inflexibility in rule } \\
\text { application }\end{array}$ & Tendency to monopolize & Restricted (interest) focus \\
$\begin{array}{l}\text { Slow pace of decision- } \\
\text { making }\end{array}$ & Disregard for externalities & Amateurism \\
$\begin{array}{l}\text { Complexity of jurisdictions/ } \\
\text { levels }\end{array}$ & $\begin{array}{l}\text { Preoccupation with short- } \\
\text { term returns }\end{array}$ & Material scarcity \\
Inclination to control & Inequality of outcomes & $\begin{array}{l}\text { Fragmentation (small scale } \\
\text { approach) }\end{array}$ \\
\hline
\end{tabular}

In the next section, the nature and challenges of PPP Projects will be described

\section{PUBLIC-PRIVATE PARTNERSHIPS}

Public-Private Partnerships (PPPs) are collaborative mechanisms in which public organizations and private entities share resources, knowledge and risks in order to achieve more efficiency in the production and delivery of products and services 
(Hartwich et al.). In the agricultural sector, frequent public-sector partners include research institutes, agricultural extension services and universities. Private-sector partners often include agro-processors, input providers, producers and trader associations, and credit providers. PPPs are a relatively new way of instigating research and development in the agricultural sector. When well executed, a PPP may offer the following advantages (Hartwich et al.):

a. Reduced costs and risks for individual business or other organizations

b. Improved relevance of R\&D efforts and faster, broader adoption of innovations

c. Complementary skills, abilities, and resources

d. New and more profitable markets

e. Improved access to knowledge and resources for smallholder farmers

Building PPPs is a cumbersome process as I have learned during the last 15 years. There are a number of critical steps to be followed, such as:

a. Identification of common interests

b. Identification of key partners around the value chain (also called the "agri-chain"), and the roles and responsibilities of each partner

c. Definition of financial and non-financial contributions by key partners

d. Determination of key indicators of success (which may different for each partner), and a common understanding how these parameters will be measured

e. Agreement on a contract between key partners which defines the PPP effort

f. Agreement on the composition of a Steering or Advisory Committee which may include stakeholders who do not contractually belong to the group of cost-sharing partners

Limitations of public funds have encouraged more and more governments across the world to use PPPs to procure rural development and social structure projects (Junxiao Liu et al.). Also, philanthropic donors such as the Gates Foundation and others follow similar strategies. However, the success of such funding strategies is not always assured. The Dutch government established a PPP Fund, the Schokland Fund, using this model. From 2008-2013 it funded 39 PPP projects, all of which were in Africa. Upon completion of the projects an independent team conducted a post-project evaluation. The evaluation was based on the contributions of each projects to one or more of the Millennium goals. Only 12 of the 39 projects $(31 \%)$ were judged "very good" or "good", 13 projects $(33 \%)$ "medium", while the rest (36\%) "insufficient" or "poor". The project implemented by Winrock's European partner, EUCORD, belonged to the top five projects. (van Gerwen \& van Ede 2013.)

When philanthropic donors co-fund agricultural PPP projects, they aim to support smallholder farmers. Figure 1 reflects this development goal. The objective of PPP projects is to convert smallholder farming into commercial farming, thereby weaning a part of the sector off of government support, such as public agricultural extension services or input subsidies.

The goal of all agricultural processing entrepreneurs is a reliable high quality yearround flow of competitively priced raw material. Smallholders have difficulty meeting this goal because of the seasonality of production, a lack of familiarity with quality standards, their high transactional costs, a lack of access to reasonably priced inputs such as improved feeds and vaccines, and a lack of access to credit. Linking smallholders into the commercial supply chain has many advantages for them. It provides an incentive for farmers to use productivity-increasing inputs thereby making the agricultural sector more competitive. It leads to an increase of income for them, thereby stimulating local rural 
economic growth. Finally, it weans them from under-funded and malfunctioning public agencies and allows the private sector to assume the role of primary service providers.

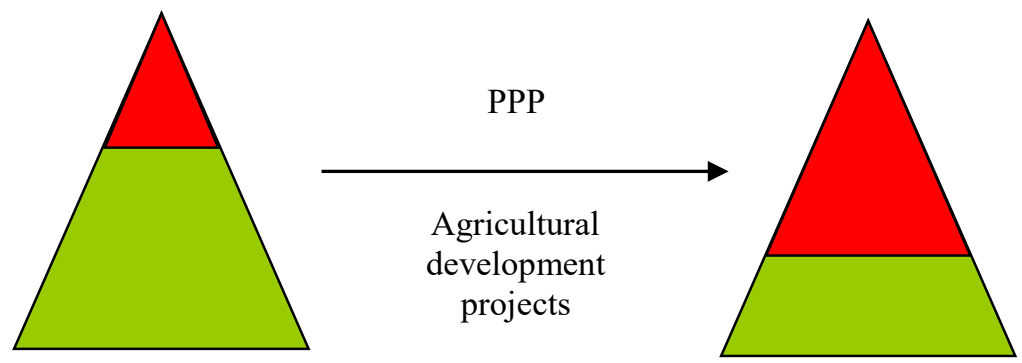

Commercial farmers

Subsistence/smallholder

Figure 1. General goal of agricultural PPP projects

One of the criticisms against agricultural PPP projects is that such projects are aimed at the better-off portion of the smallholder population rather than the poorest of the poor. In other words, these projects are not likely to reach the "bottom of the pyramid". A counter-argument is that by helping the relatively more prosperous smallholder farmers to help themselves, there are more public resources left to support the very poor.

\section{Value chains}

Value or supply chains encompass the full range of activities and services required to bring a commodity from its production to its final use. In other words, a value chain refers to the system and resources required to move a product or service from producer to customer or consumer. The 'value chain' concept implies a list of actors who add value along the chain, as well as the manner in which this value is added. From the private sector perspective, value chains are often identified as "supply chains". From a research perspective, the term 'value chain' has more appeal, since its analysis includes the identification of stakeholders in the value-creation process. The design of value chains in the livestock sector is similar to the market system figures presented by Tjeppy Soedjana et al. in 1984 and later expanded by Knipscheer, Soedjana et al. in 1987. The design consists of a compilation of arrows between the main market actors involved in bringing the livestock product from farmers to consumers. It defines the role that each actor performs (e.g. collection, transport, storage, quality differentiation, processing, labeling, distribution, etc.). Pervaiz Amir et al. (1989) explained the importance of market assessments in their training manual "Conducting On-Farm Animal Research: Procedures and Economic Analysis" (1-244).

All processing entrepreneurs wish for a reliable high quality year-round flow of competitively priced raw material. Smallholders have difficulty meeting such requirements because of high transaction costs, and a lack of familiarity with quality requirements, reliable access to reasonably priced inputs such as improved feed and drugs, and access to credit.

Winrock International has gained valuable experience in helping smallholders participate in supply chains and gain access to new markets. See Figure 2. 
Winrock Interventions Linking Smallholders to Value Chains

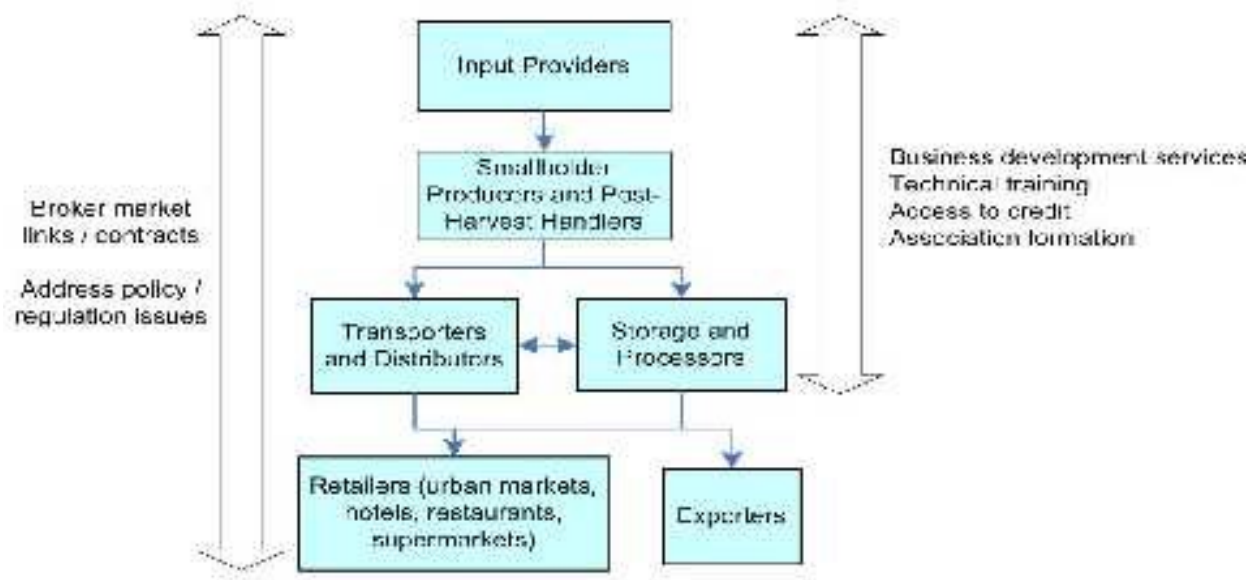

Figure 2. Generic example of a value chain

This approach centers on four integrated strategies: (a) Organizing stakeholders along the supply chain (e.g. Round Table meetings and/or Alliance meetings) and identifying one or more committed private sector companies; (b) Identifying clusters of smallholder production regions (in order to minimize transport and transaction costs); (c) Facilitating access to high quality inputs (including credit); (d) Leveraging government extension support; (e) Serving as broker and problem solver among various stakeholder during the initial phase of collaboration when their roles and practices are not yet well defined or understood. The example of a value chain in Figure 2 is generic. A much more elaborate and detailed example appears in the next section where the Kenya indigenous poultry value chain is described (Figure 3).

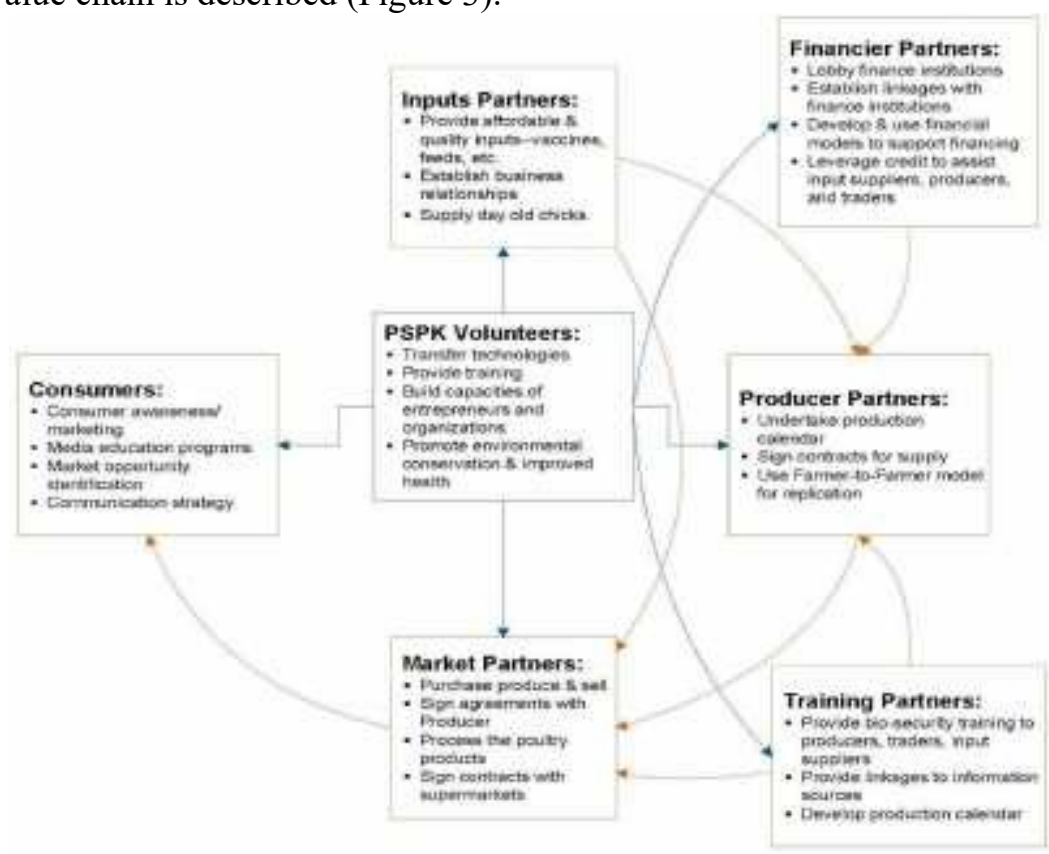

Figure 3. PSPK market-based value chain model 


\section{Example: The PSPK and the indigenous poultry sector in Kenya}

Winrock International's USAID-funded Partnership for Safe Poultry in Kenya (PSPK) Program (2009-2011) was a 30-month long pilot project designed to promote safe poultry production, increase income, and improve nutrition for smallholder families. PSPK initiated training and technical expertise for thousands of Kenyan smallholder farmers, coupled with training and support to various government entities. This dual focus created a strong movement within the poultry sector in Kenya, setting the stage for further growth and sustainable impact. In Kenya, up to $75 \%$ of poultry farmers (a majority of whom are women) were accustomed to raising small, free-roaming flocks that were extremely susceptible to disease. These backyard poultry farmers were beyond the reach of public sector extension services and had little or no support to improve their production efficiency while diseases claimed a large toll of their poultry. Most of the information below was presented in Winrock's Final Project Report to USAID (2011). PSPK project objectives included:

- Facilitating Kenyan poultry sector stakeholders (including feed mills and traders/consolidators) to work together to define opportunities and challenges, define sector growth goals, and commit to action to meet sector goals.

- Building the capacity of the Kenya Poultry Farmers Association (KEPOFA) to define the needs of rural, smallholder poultry producers and manage programs and resources on their behalf.

- Enabling and empowering smallholder producers to invest in facilities and appropriate technology and to apply best management practices in order to increase productivity and profitability and assure the biosecurity of their flocks and the safety of poultry, meat, and eggs.

- Promoting Kenyan indigenous poultry meat and eggs from bio-secure smallholder flocks among Kenyan consumers in order to be recognized for their high quality and value.

- Ensuring that smallholder poultry producers have access to needed market information and training.

\section{Value chain research}

PSPK funded a study to identify market needs and consumer preferences, and to determine the competitive position of Kenyan poultry meat and egg products. The study focused on end-market opportunities in Nairobi, the largest urban market in Kenya, and identified a growing demand for poultry meat and eggs from indigenous birds and biosecure smallholder flocks. This information guided the PSPK-established farmer demonstration groups to focus their efforts on market needs and was also useful in informing policy advocacy efforts. The study findings were shared with various stakeholders to inform producers and other actors about the market requirements and consumer preferences. An important finding was that hotels and restaurants were willing to purchase indigenous poultry meat at higher prices because of their superior taste. A new key strategy among selected intermediate poultry traders was their willingness to pass on part of the higher consumer prices to the poultry producers rather than trying to keep all the value-added incentives in their own pockets. Figure 3 shows the value chain map which resulted from this research activity.

Some value chain maps attempt to include more information, such as price differences at various levels of the value chain. See Hartwich at al. (2007) for a very 
useful training manual for PPPs. The more information that is included in the chart, the more complicated it becomes. A value chain map or chart should be updated on a regular basis. As the technical advisors to the project were recruited by Winrock as volunteer experts, they were placed in the center of Figure 3.

\section{Stakeholders}

Groups such as the Kenya Poultry Farmers Association (KEPOFA) and Agricultural Business Development (ABD) willingly provided services to help farmers improve practices, increase productivity and competitiveness, and generate more sales. KEPOFA had about 1600 members comprised mainly of backyard poultry producers. Its mission is to contribute to socio-economic empowerment of its members by addressing sector constraints related to production, processing, and marketing through lobbying, advocacy, and the delivery of quality services (see below).

ABD is a community-based organization with a mission to increase incomes for smallholder farmers. Over the last fifteen years, ABD has been facilitating the development of agricultural value chains, including those for indigenous chickens, for 645 members. It provides support to poultry producers by helping them form groups and linking them to animal health services.

AKEFEMA (Association of Kenya Feed Manufacturers) is an industry association that brings together licensed feed manufacturers. The association was registered in 2004 in response to a realization that feed manufacturers have an important role in quality input production distribution and client capacity building. PSPK provided ongoing support to AKEFEMA, to strengthen its role in self-regulating the Kenyan feed milling industry. Over the course of the program, PSPK fielded five volunteer experts to support AKEFEMA, particularly in the areas of feed quality, alternative feed formulations, and organizational development. These efforts have created and strengthened important linkages between AKEFEMA, its members, and feed laboratories. The support led to the development of new feed formulations for the indigenous poultry sector in Kenya. These efforts did result in a 23\% increase in AKEFEMA's membership.

\section{New technologies: Biosecurity demonstration farms}

The best way to extend new technologies is to learn by doing, i.e. demonstrations managed by farmers, preferably in groups. During the project, PSPK selected 11 groups (in 9 districts) to serve as biosecurity demonstration farms. For each group (about 20 members per group), one member was selected by the group to lead and manage the group demonstration farm; most of these leaders were women. PSPK prioritized pilot farms that had at least $50 \%$ female participation. This added to the success of the program and resulted in a greater impact on the family, as increased income was often spent on family health or children's education. The groups included vulnerable populations, such as people living with HIV/AIDS and women-headed households. All new technologies introduced by PSPK (including biosecurity measures) were low-cost and therefore feasible for many smallholder farmers to implement. The demonstration farms were also encouraged to develop business plans using a financial model developed by PSPK and follow an agreed-upon supply schedule with identified buyers, a form of contract farming. Dubbed the "chicken bible" by some PSPK beneficiaries, the financial model provides an easy way to analyze costs and profit against variable inputs and flock sizes. PSPK implemented the financial model with each of the 11 demonstration groups. Each group member provided information on his/her current poultry flock size and costs; the 
information was used to produce a profitability analysis using the financial model. This information was shared with each respective farmer and the group as a whole. During this process, PSPK established guidelines on the minimum flock size (at least 27 birds per farmer) to break even. PSPK therefore recommended a minimum flock size of 30 birds with commercial feed supplementation. With that flock size, the net income after 16 weeks would be Ksh 1991, while the profit margin was found to be on average 12\% (about Ksh 18 per day) with a $42 \%$ return on investment. (At the time of the project, USD $1.00=$ approximately Ksh 65). Because of PSPK training and technical assistance, all the demonstration farms are thriving. As farmers have adopted the biosecurity measures and safe poultry production practices piloted at the demonstration farms, they have decreased mortality rates of their chickens, increased and improved production, and increased sales. This has resulted in increased incomes, improved nutrition, and in some cases, the establishment of new poultry businesses. Participating farmers have enthusiastically expressed their gratitude and shared thoughts on how PSPK has positively impacted their lives. Many demonstration farms have received visitors from neighboring farmers, thus multiplying the overall spread effect of these PSPK-supported activities. Chick mortality decreased from about $50 \%$ to less than $10 \%$, the average price increased by $7.5 \%$ per $\mathrm{kg}$ of bird live weight, and poultry numbers among the 291 members (57\% females) of the demonstration farms increased by as much as $72 \%$. Via these demonstration farms up to 7,000 households have been reached indirectly. In short, the project has proved that a previously ignored smallholder livestock sector can be turned around and become a profitable business.

\section{Impact on animal feed industry}

The price of animal feed in Kenya is high because both livestock and humans depend on maize. To address this constraint, PSPK worked with AKEFEMA to develop a database of raw materials for feed formulation and to develop formulations using the identified raw materials, thus providing an alternative to maize (corn). The formulations were developed and sent to AKEFEMA members to further pilot and improve. PSPK also provided training to feed millers on feed formulations, rations, and the importance of mineral nutrition in livestock production. Participants indicated that this was the first time that a systematic analysis of locally-available materials for feed had been undertaken in Kenya. Many small feed mills in Kenya have their own sanitary challenges. For example, prior to the PSKP Project, the Tich Nam Mill was infested with rats and weevils, and was surrounded by a thicket of bushes. Following a PSPK technical expert recommendation, Tich Nam's Marketing Manager noted, "We managed to eliminate rodents, cleared the bushes, fenced off the farm, and introduced foot baths at the poultry unit." The unit now sells feed for indigenous birds using locally available raw materials. Tich Nam promoted their feeds at various venues, which has resulted in regular sales to agro-vet stores and individual agents. Average sales increased from $500 \mathrm{~kg} /$ day to $1400 \mathrm{~kg} /$ day. In addition, Tich Nam, in collaboration with other stakeholders, launched a training program for poultry farmers. The purpose of the training was to make farmers aware of the nutrition value of various feeds. PSPK demonstrated how investments in the poultry sector can lead to income generation, improved nutrition, and increased employment, while also reducing the threat of Avian Influenza and other diseases. This strategy ultimately led to the program's success. The PSPK evaluation stated, "Selecting the adoption of biosecurity measures by farmers as the best vehicle to increase income was exactly the right decision." 


\section{Strengthening the organizational management and governance of KEPOFA}

The Kenya Poultry Farmers Association (KEPOFA) is an association comprised of mainly backyard poultry producers, with the mission to contribute to socio-economic empowerment of its members by addressing sector constraints related to poultry production, processing, and marketing through lobbying, advocacy and delivery of quality services. Part of PSPK's strategy was to provide targeted assistance and training to KEPOFA, to strengthen its role as a facilitator and service provider for Kenyan smallholder poultry farmers. As a result of PSPK activities, KEPOFA membership increased by $57 \%$, vastly exceeding the original project target of $10 \%$. This translated to a $110 \%$ increase in the number of household members benefiting from KEPOFA. PSPK's activities with KEPOFA included conducting an organizational assessment of the association, reviewing the association's strategic plan, developing a business development model for its members, and establishing a database of Kenyan poultry farmers.

\section{CONCLUSION AND LESSONS LEARNED}

The Partnership for Safe Poultry in Kenya (PSPK) Program is an example of a successful PPP project. Winrock International was the implementing NGO with cofunding provided by USAID (U.S. Agency for International Development). The project enabled previously ignored livestock smallholder producers to invest in facilities and appropriate technologies and apply best management practices. The project demonstrated that it was possible to assure the biosecurity of their flocks and the safety of poultry meat and eggs - while at the same time increasing productivity, profitability and income.

Within a span of two years, indigenous Kenyan poultry meat and eggs from biosecure smallholder flocks became recognized for their high quality and gained a premium value. These added values were passed on to producers' groups. A key instrument was the development of bio-secure demonstration farms where chick mortality decreased significantly, average price increased by $7.5 \%$ per $\mathrm{kg}$ of bird live weight, and poultry numbers increased by more than $70 \%$. Via these demonstration farms, up to 7,000 households were reached indirectly. The project proved that a previously ignored smallholder livestock sector can be turned around and become a profitable business.

\section{Lessons learned}

Key lessons learned include the following:

- An important lesson from PSPK was that producers will adopt biosecurity measures if there is a financial incentive. The dual focus on smallholder production and measures to address biosecurity threats was key to increasing competitiveness and incomes. A major development was the willingness by intermediate traders to pass on a portion of the added value of indigenous chicken meat to the producers.

- Poultry production, one of the few activities that women can engage in without the involvement of men, proved an important economic and leadership opportunity for women.

- Group forming of farmers was essential e.g. common collection point, common demonstration plot/farm, minimizing transport and reducing storage costs. However, such groups do not need to become formal cooperatives as these organizations tend to become bureaucratized and thereby inefficient. 
- Demonstration farms/fields were an effective way of teaching improved technologies.

- Access to credit was an essential extension tool for improving smallholder production and promoting commercialization.

- Access to markets and market information are critical to smallholder production interests. Multilevel contracts (formal or informal) increased trust and transparency.

- The focus on a single value chain contributed to the impact of the project and enabled the use of specialized technical experts. However, such single crop/animal focus is costly.

- Intermediate partners were key to a better-functioning value chain. These can be "bulkers", or "consolidators", but can also serve as trainers/extension agents, demonstration coordinators, and even as input and credit providers. Winrock's experience shows that such partners should preferably live within the targeted farmer community where they are known and trusted.

- The role of the NGO partner (Winrock) appeared to be essential in serving as an honest broker between farmers and private sector partners and other stakeholders along the value chain, e.g. the agricultural extension agency.

- Although the project did not reach the rural poorest of the poor (who typically do not own livestock or even poultry), the introduced innovations resulted in increasing the earnings of medium income level farmers in a significant way, thereby improving the general overall village income.

\section{REFERENCES}

Amir P, Knipscheer HC. (1989). Conducting On-Farm Animal Research: Procedures and Economic Analysis. Winrock International and International Development Research Center.

Van Gerwen F, van Ede S. (2013). Evaluation of Schokland and Millennium Agreements 2008-2013. Final Report, Dutch Ministry of Foreign Affairs, The Hague.

Hartwich F, Tola J, Engler A,Gonzales C, Ghezan G, Vazquez-Alvarado JMP, Silva JA, de Jesus Espinoza J, Gottret MV. (2007). Building Public-Private Partnerships for Agricultural Innovation. Washington D.C. (USA): International Food Policy Research Institute.

Junxiao L, Love PED, Smith J, Regan M, Dutrisna M. (2014). Public-Private Partnerships: a review of theory and practice of performance measurement. Int J Product Perform Manag. 63(4):499-512.

Kartamulia I, Misniwaty A, Knipscheer HC. (1995). Development of the Private Animal Health Network in North Sumatra. Agric Hum Values. 12(2):39-44.

Knipscheer HC, Nu Nu S, Webb SH, Karo Karo S.(1996). Economic Potential of Small Ruminant Agribusiness in South-East Asia. In: Merkel R, Soedjana TD, Subandriyo, editors. Small Ruminant Production: Recommendations for South-East Asia.

Knipscheer HC, Sabrani M, Soedjana TD, De Boer AJ. (1987). Small Ruminant Market System in Indonesia. Agric Syst. 25:87-103.

Soedjana TD, Knipscheer HC, Sugianto. (1984). The Marketing of Small Ruminants in East Java. In: Sheep and Goats in Indonesia. p. 179-183.

Winrock International. (2011). Partnership for Safe Poultry in Kenya (PSPK) Program. Final Report (submitted to USAID, Washington, DC). 